\title{
An investigation into the factors that encourage learner participation in a large group medical classroom
}

Jennifer Moffett

John Berezowski

Dustine Spencer

Shari Lanning

Ross University School of Veterinary Medicine, West Farm, St Kitts, West Indies
Correspondence: Jennifer Moffett Ross University School of Veterinary Medicine, PO Box 334, West Farm, St Kitts, West Indies Email jmoffett@rossvet.edu.kn
This article was published in the following Dove Press journal:

Advances in Medical Education and Practice

II March 2014

Number of times this article has been viewed

Background: Effective lectures often incorporate activities that encourage learner participation. A challenge for educators is how to facilitate this in the large group lecture setting. This study investigates the individual student characteristics involved in encouraging (or dissuading) learners to interact, ask questions, and make comments in class.

Methods: Students enrolled in a Doctor of Veterinary Medicine program at Ross University School of Veterinary Medicine, St Kitts, were invited to complete a questionnaire canvassing their participation in the large group classroom. Data from the questionnaire were analyzed using Excel (Microsoft, Redmond, WA, USA) and the R software environment (http://www.r-project.org/).

Results: One hundred and ninety-two students completed the questionnaire (response rate, $85.7 \%$ ). The results showed statistically significant differences between male and female students when asked to self-report their level of participation $(P=0.011)$ and their confidence to participate $(P<0.001)$ in class. No statistically significant difference was identified between different age groups of students $(P=0.594)$. Student responses reflected that an "aversion to public speaking" acted as the main deterrent to participating during a lecture. Female participants were 3.56 times more likely to report a fear of public speaking than male participants (odds ratio 3.56, $95 \%$ confidence interval 1.28-12.33, $P=0.01$ ). Students also reported "smaller sizes of class and small group activities" and "other students participating" as factors that made it easier for them to participate during a lecture.

Conclusion: In this study, sex likely played a role in learner participation in the large group veterinary classroom. Male students were more likely to participate in class and reported feeling more confident to participate than female students. Female students in this study commonly identified aversion to public speaking as a factor which held them back from participating in the large group lecture setting. These are important findings for veterinary and medical educators aiming to improve learner participation in the classroom. Potential ways of addressing this challenge include addition of small group activities and audience response systems during lectures, and inclusion of training interventions in public speaking at an early stage of veterinary and medical curricula.

Keywords: age, class size, interaction, lecture, public speaking, sex, veterinary

\section{Introduction}

The large group lecture as a teaching method in higher education has been viewed with somewhat mixed opinions. Educationalists argue that lectures can fail to engage students, and are predisposed to creating a passive learning experience. ${ }^{1,2}$ However, lecturing is a low-cost mode of teaching, which is well accepted by students and faculty; ${ }^{3}$ thus, it is likely to remain a staple of higher education curricula. What many 
agree on, however, is that lectures best facilitate learning when thought is invested into the way material is presented. ${ }^{1}$ For example, the medical education literature informs us that effective lectures often incorporate activities that facilitate active learning and encourage learner participation. ${ }^{4}$ Such participation in the classroom has been linked to a wide variety of positive educational results for learners, including increased levels of content acquisition and retention of material, and development of higher order cognitive functions such as critical thinking. ${ }^{5,6} \mathrm{~A}$ challenge for educators is how to facilitate learner participation in the large group lecture setting.

We propose that a first step in meeting this challenge is to better understand the underlying factors involved in encouraging (and dissuading) learners to interact, ask questions, and make comments in class. The existing higher education literature suggests that individual student characteristics such as age and sex are potential factors affecting classroom participation. ${ }^{7}$ This study aims to determine if these factors affect self-reported participation in the large group veterinary education classroom. In addition, the study aims to assess if the stage at which a learner is in the curriculum (ie, junior versus senior) has an effect on their participation. Finally, the investigators elicited ideas from veterinary students with regard to factors that aid or impede their participation in the large group setting. To the researchers' knowledge, the factors affecting participation in a large group classroom have not been reported in detail in the medical education literature.

\section{Materials and methods}

\section{Participants}

A total of 224 students enrolled in a Doctor of Veterinary Medicine program at Ross University School of Veterinary Medicine, St Kitts, were invited to participate in the study. The student population at Ross University School of Veterinary Medicine consists of $74 \%$ female students and $36 \%$ male students. From a cultural perspective, $70 \%$ of students are categorized as White (non-Hispanic), 14\% Asian or Pacific Islander, 6\% Hispanic, and 1\% Black or AfricanAmerican. ${ }^{8}$ Nineteen percent of students did not identify themselves as members of a specific demographic group. A questionnaire was offered to two cohorts of students, ie, a semester 1 class and a semester 6 class. The students were allocated a 15 -minute period during the normal course schedule to complete the questionnaire. Both semester 1 and semester 6 cohorts were surveyed in April 2012, during week 14 of the spring semester at Ross University School of Veterinary Medicine.

\section{Questionnaire design and use}

A review of the literature determined that there was a lack of validated questionnaires for measuring classroom participation in medical education settings. A questionnaire was designed by the researchers to assess student perceptions of their participation in the large group classroom. The questionnaire consisted of ten items subdivided into three types, ie, demographic, Likert-type scale, and open-ended. To ensure content validity, the questionnaire was reviewed by a panel of educational researchers and then tested by a group of students $(n=13)$. The final questionnaire was approved by the institutional review board of Ross University School of Medicine, Dominica.

The questionnaires were administered to students alongside an informed consent document which communicated that the confidentiality of all participants would be protected, and that only collated data from the study would be presented in research outputs. All hard copy data were stored in a locked file cabinet, and electronic data were stored on a secure, password-protected computer.

Participants were asked to report their age and sex. They were also asked to rate their perception of their participation in class and confidence to participate using a series of 5-point Likert-type scale questions, from 1 ("never") to 5 ("always"). Participation was defined within the questionnaire as occasions when a student "answered an instructor's question, asked a question, or made a comment on the material presented". Participants were also asked to complete two open-ended enquiries: "The main thing that deters me from participating in a lecture is ..." and "The main thing that makes it easier for me to participate in a lecture is ...".

\section{Statistical analysis}

During the design stage, Cronbach's alpha was used to quantify the internal reliability of the total questionnaire. Descriptive statistics were calculated using Microsoft Excel (Microsoft, Redmond, WA, USA), with tests for statistical significance and 95\% confidence interval (CI) estimates calculated using the $\mathrm{R}$ software environment (http:// www.r-project.org/). The Mann-Whitney $U$-test was used to test for statistically significant differences in Likerttype scores between sex and semester groups (two groups each). Kruskal-Wallis rank sum tests were used to test for statistically significant differences in Likert-type scores for age groups (four groups). Two-tailed Fisher's exact tests were used to analyze nominal data. For all statistics, a two-sided $P$-value $<0.05$ was considered to be statistically significant. 


\section{Results}

Cronbach's alpha for the questionnaire was calculated at $\alpha=0.9$, indicating that there was significant consistency in the items used within the survey instrument. In all, 192 students $(85.7 \%)$ completed the questionnaire. The largest age group consisted of students aged 23-27 years, which made up $59.9 \%$ of the study population, followed by the age group 28-32 years (25.5\%). The semester 1 cohort $(n=141)$ contained a greater proportion of younger students than the semester 6 cohort $(\mathrm{n}=83)$, and the ages of the two cohorts of students were significantly different $(P<0.001)$. The study population was predominantly female, with five times more female participants than male (32 male and 160 female participants). There was also a statistically significant difference in the proportion of males in the two semesters. There were 2.67 times more male students in semester 6 than in semester 1 (odds ratio [OR] 2.67, 95\% CI 1.23-5.78, $P=0.019$ ).

In response to the Likert-type scale question "I participated in lectures", the median score for all participants was 3.0. There was a statistically significant difference $(P=0.011)$ in scores between male and female participants. The median score was 3 for males and 2.5 for females. The distribution of responses to this question for male and female students is shown in Figure 1.

There was also a statistically significant difference between the students in the different class cohorts. Semester 6 students had higher self-reported participation scores than semester 1 students $(P<0.001)$. The median score was 3.0 for semester 6 students and 2.0 for semester 1 students. Although there were differences in scores between the age groups, they were not statistically significant $(P=0.457)$.

In response to the Likert-type scale question "I felt confident enough to participate in lectures", the median score for all participants was 3.0. There was a statistically significant difference $(P<0.001)$ in scores between male and female participants. The median score was 4.0 for males and 3.0 for

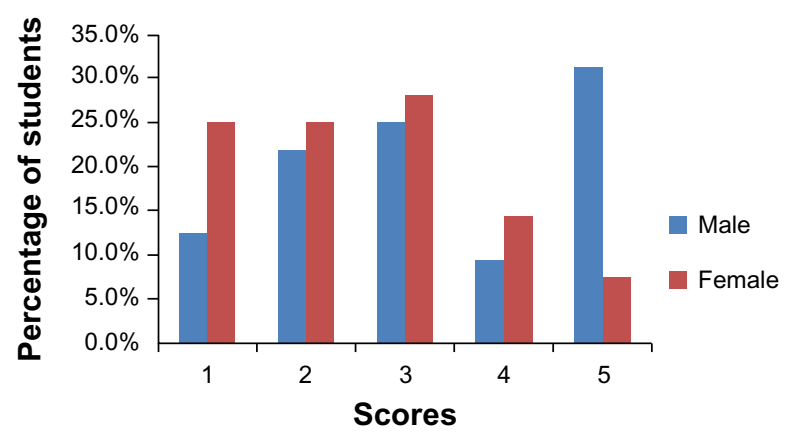

Figure I Distribution of responses to enquiry "I participated in lectures" for male and female students. females. The distribution of responses to this question for male and female students is shown in Figure 2. No statistically significant difference was identified between the semester 1 and semester 6 student groups $(P=0.062)$ nor between the four age groups $(P=0.594)$.

Responses to the open-ended enquiries were organized using a coding scheme whereby responses were reviewed for common themes and allocated to a category which grouped together conceptually similar terms. Tables 1 and 2 illustrate this coding scheme alongside typical participant responses for the questions.

When students were asked to name "the main thing that deters me from participating in a lecture", the most common response category overall was "aversion to public speaking", which accounted for $34.5 \%$ of all responses. When responses to this question were analyzed according to sex, the most common response category for female participants was "aversion to public speaking" (38.2\%), whilst male participants were more likely to leave a blank response $(17.6 \%$, Table 3). Female students were 3.56 times more likely than male students to fall into the "aversion to public speaking" category (OR 3.56, 95\% CI 1.28-12.33, $P=0.01$ ); however, apart from this finding, there were no statistically significant differences between male and female participants (Table 3). There were no statistically significant differences between the responses of semester 1 and semester 6 students, or across the four age groups for this question.

When students were asked to name "the main thing that makes it easier for me to participate in a lecture", the most common response categories overall were "smaller sizes of class, small group activities" (18.9\%) and "other students participating" (18\%). There were differences in responses between males and females, although only the response category "smaller sizes of class, small group activities" was significantly different (Table 4). Female participants were 9.1 times more likely to fall into this category than male

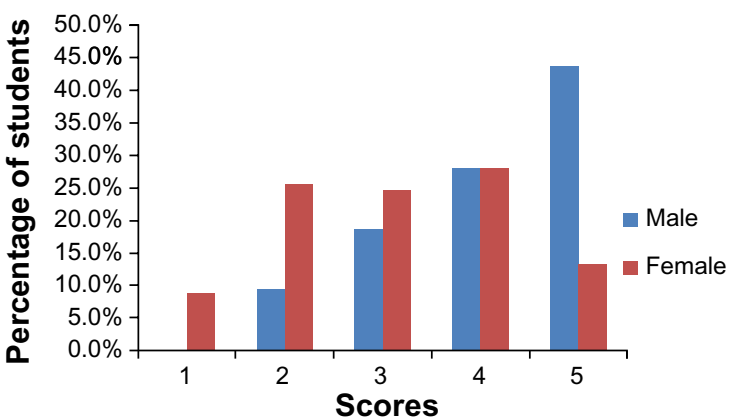

Figure 2 Distribution of responses to enquiry "I felt confident enough to participate in lectures" for male and female students. 
Table I Categorization of participant responses to: "The main thing that deters me from participating in a lecture is ..."

\begin{tabular}{|c|c|}
\hline Category & Typical participant response \\
\hline Aversion to public & “I don’t like public speaking” \\
\hline speaking & "Speaking in front of a big audience" \\
\hline \multirow[t]{2}{*}{ Lecture factors } & "Lecture topic" \\
\hline & "Lectures are too long" \\
\hline Lecture venue & "Not wanting to have to yell cross the room" \\
\hline Lecturer and/or & "The constantly changing professor/ \\
\hline presentation style & $\begin{array}{l}\text { lecturer made it difficult to determine what } \\
\text { type of participation they wanted" }\end{array}$ \\
\hline \multirow[t]{3}{*}{ information to contribute } & $\begin{array}{l}\text { "I have less experience/qualifications than } \\
\text { the other students" }\end{array}$ \\
\hline & "I have little experience in a clinic therefore \\
\hline & I have little to add to the conversation" \\
\hline Not knowing answer & "Afraid I will not be correct and not saying \\
\hline to lecturer questions & what they are looking for" \\
\hline Student motivation & "How much energy I had that day" \\
\hline factors & "Seemed lecture did not pertain to me" \\
\hline Student personality & "I'm not outspoken" \\
\hline factors & "I'm shy" \\
\hline \multirow[t]{2}{*}{ Peer factors } & $\begin{array}{l}\text { "Not wanting to take away someone else's } \\
\text { opportunity to participate" }\end{array}$ \\
\hline & "The same people continually jump right into \\
\hline \multicolumn{2}{|l|}{ Other or meaning unclear } \\
\hline \multicolumn{2}{|l|}{ Blank or comment without } \\
\hline further information & \\
\hline
\end{tabular}

Table 2 Categorization of participant responses to: "The main thing that makes it easier for me to participate in a lecture is ..."

\begin{tabular}{|c|c|}
\hline Category & Typical participant response \\
\hline Audience response & "Using clickers" \\
\hline systems/“clickers" & "When we use the clickers in class" \\
\hline Being called & "When a direct question is asked" \\
\hline on to participate & "Asked to participate" \\
\hline Feeling confident, & "Personal experience pertaining to the topic" \\
\hline knowledgeable & "Interest and knowledge about what is being \\
\hline about topic & talked about" \\
\hline Lecture & "Being comfortable around my colleagues" \\
\hline environment & "Comfortable setting" \\
\hline \multirow[t]{2}{*}{ Lecture factors } & "Talking about subjects that were not personal" \\
\hline & "Having lecture notes to pre-read before class" \\
\hline Lecturer and/or & "Friendliness of professors" \\
\hline presentation style & "The openness of the professors" \\
\hline Specific use of & “Open-ended questions" \\
\hline open-ended questions & "Open questions" \\
\hline Other students & "When a lot of other people are participating" \\
\hline participating & $\begin{array}{l}\text { "Other people (peers) also wanting to } \\
\text { contribute to the lecture" }\end{array}$ \\
\hline Smaller sizes of class, & "Smaller class sizes or groups" \\
\hline small group activities & "Smaller group activities" \\
\hline $\begin{array}{l}\text { Student personality } \\
\text { factors }\end{array}$ & $\begin{array}{l}\text { "Not sure there is anything. I'm just quiet in } \\
\text { nature" }\end{array}$ \\
\hline & “I'm opinionated" \\
\hline \\
\hline \multicolumn{2}{|l|}{ without further } \\
\hline information & \\
\hline
\end{tabular}

Table 3 Distribution of student responses to the main deterrent to participating in lecture, grouped by sex

\begin{tabular}{llll}
\hline Response & \multicolumn{3}{l}{ Percent } \\
\cline { 2 - 4 } & Males & Females & Total \\
\hline Aversion to public speaking & 14.7 & 38.2 & 34.5 \\
Lecture factors & 11.8 & 13.4 & 13.2 \\
Peer factors & 5.9 & 11.3 & 10.5 \\
Blank or comment without further & 17.6 & 8.6 & 10 \\
information & & & \\
Student personality factors & 2.9 & 8.6 & 7.7 \\
Not knowing answer to lecturer questions & 14.7 & 5.9 & 7.3 \\
Student motivation factors & 11.8 & 3.8 & 5.0 \\
Lecturer and/or presentation style & 5.9 & 4.3 & 4.5 \\
Perception of lack of information & 8.8 & 3.8 & 4.5 \\
to contribute & & & \\
Lecture venue & 0 & 1.6 & 1.4 \\
Other or meaning unclear & 5.9 & 0.5 & 1.4 \\
& 100 & 100 & 100 \\
\hline
\end{tabular}

participants (OR 9.1, 95\% CI 1.42-379.03, $P=0.008$ ). There were several statistically significant differences between the responses of the two semester cohorts. For example, semester 1 students were 5.75 times more likely to report "smaller sizes of class, small group activities" (OR 5.75, 95\% CI 2.12-19.58, $P<0.01)$ and "audience response systems/"clickers"' (95\% CI 1.09-21.41, $P<0.03$ ) than students in semester 6 . Semester 6 students were more likely to report "other students participating" (95\% CI 1.56-7.12, $P<0.001)$ and "lecture environment" (95\% CI 1.36-11.68, $P<0.007)$ than semester 1 students.

The data also revealed that there was an association between certain student response categories with regard to factors that made it easier, or more difficult, to participate

Table 4 Distribution of student responses to the main incentive to participating in lecture, grouped by sex

\begin{tabular}{llll}
\hline Response & \multicolumn{2}{l}{ Percent } & \\
\cline { 2 - 4 } & Males & Females & Total \\
\hline $\begin{array}{l}\text { Smaller sizes of class, small group } \\
\text { activities }\end{array}$ & 2.9 & 21.6 & 18.9 \\
$\begin{array}{l}\text { Other students participating } \\
\text { Blank or comment without further }\end{array}$ & 20.6 & 17.5 & 18 \\
information & 23.5 & 10.8 & 12.7 \\
Audience response systems/“clickers” & 2.9 & 10.3 & 9.2 \\
Feeling confident, knowledgeable & 8.8 & 9.3 & 9.2 \\
about topic & & & \\
Lecture environment & 5.9 & 9.8 & 9.2 \\
Lecture factors & 11.8 & 8.8 & 9.2 \\
Being called on to participate & 8.8 & 8.2 & 8.3 \\
$\begin{array}{l}\text { Open-ended questions } \\
\text { Student personality factors }\end{array}$ & 11.8 & 1.5 & 3.1 \\
Lecturer and/or presentation style & 0 & 1.5 & 1.8 \\
& 100 & 100 & 100 \\
\hline
\end{tabular}


in the large group classroom. For example, students in this study who reported an "aversion to public speaking" as the main deterrent to participation were 5.91 times more likely to report "smaller class size or smaller group activities" as the main factor that would make participation easier for them (95\% CI 2.67-13.85, $P<0.001)$.

Finally, there were statistically significant differences in responses associated with the different age groups. "Smaller sizes of class, small group activities" was most commonly reported for those aged 18-27 years, who were 2.47 times more likely to make this response than the other students (OR 2.47, 95\% CI 1.05-6.55, $P=0.03$ ). "Other students participating" was most commonly reported for those aged 28-32 years (OR 2.98, 95\% CI 1.39-6.34, $P=0.004$ ). "Lecture factors" was the most commonly reported category for students aged 33 years and older, but the difference was not statistically significant.

\section{Discussion}

\section{Sex factors}

A core aim of this study was to explore factors affecting self-reported learner participation in the large group veterinary education classroom. One of the main findings was the different responses to questions between male and female learners. Male students reported that they were much more likely than their female colleagues to participate and to feel confident enough to participate in class. There is little information on the effect of sex on participation in the medical education literature, and within the broader field of higher education literature there have been contradictory findings. Whilst some studies have documented that female students participate less often than males, ${ }^{9,10}$ others have not found a difference. ${ }^{7}$ Although the reasons for increased participation amongst male students in the current study are unclear, one potential explanation may come from the finding that female participants in this study reported a significantly higher level of discomfort than the male participants when speaking up in front of their peers. This result is interesting, but to some extent not surprising. Existing sociological research suggests that, in general, women report a significantly greater fear while talking or performing in front of an audience than men. ${ }^{11}$ This sex difference is something that may not be immediately obvious to educationalists charged with designing professional health curricula. However, it is an important consideration, particularly for those involved in veterinary and medical education, given that a worldwide global feminization of both professions has taken place. ${ }^{12-14}$ The data also reveal that many students, male and female, who reported an aversion to public speaking also reported a preference for smaller class sizes or smaller group activities. Unfortunately it is not possible to conclude whether or not this association is causal from the current data. It is feasible that smaller class sizes or increased small group activities may reduce students' fear of speaking in public; however, further research is required to investigate this specific association. The current study did identify specific activities and teaching modalities that may assist students with large group participation. These include smaller groups and small group activities, involvement of other students, and use of audience response systems. Although it would be difficult to change the overall number of students within the lecture environment, there are ways of incorporating some facets of small group teaching into the large group setting; for example, team-based learning, breakout groups (pair share and buzz groups), and games or quizzes. ${ }^{15,16}$ Audience response systems ("clickers") are another popular and effective way of using technology to promote learner interaction. ${ }^{15}$ In addition, those involved with curriculum design could consider addition of training interventions that build confidence in public speaking from an early stage in the curriculum. Although public communication has been identified as a core competency for veterinarians, ${ }^{17,18}$ there is scarce evidence in the literature of veterinary students' proficiency in this area.

\section{Age factors}

No statistically significant difference was found between the different student age groups with regard to their self-reported levels of participation or their confidence to participate. This was a surprising finding, given that previous studies have identified that older students tend to have a higher level of classroom participation than younger students. ${ }^{7}$ It is possible that this finding is linked to the relatively small sample size of older students in our study. The different age groups did, however, reveal different preferences with regard to how to encourage participation. For example, participants in the youngest age group were more likely to rate small groups as an incentive to participate compared with older students This difference may reflect developments in educational practice, ie, younger students are more likely to have been exposed to a school system that utilized small group teaching methods than older students. However, this theory needs further investigation.

\section{Student-stage and semester-level factors}

There were several differences between the semester 1 and semester 6 cohorts, in particular that senior students 
were more likely to participate in class than their junior counterparts. Our study suggests that it is unlikely that the increased age profile between semesters is responsible for this difference. However, it is possible that sex played a role in the finding, given that there were a higher proportion of male students in the semester 6 group than in the semester 1 group. Another reason proposed for this higher level of participation amongst more senior students was that of increased group cohesion, ie, semester 6 students, who at the time of the survey had been enrolled at Ross University School of Veterinary Medicine for at least 20 months, were more likely to have formed stable and closer relationships with each other than semester 1 students, who had been enrolled for only 4 months.

Finally, semester 1 students reported a greater preference for smaller groups and small group activities. Again, this finding could be related to sex since there were a higher proportion of female students who indicated a preference for smaller groups in semester 1 than in semester 6 . It is also possible that this difference was due to the size of the class cohorts and the overall number of students in the lecture setting. The semester 1 group $(n=141)$ was much larger in size than the 6 semester group $(n=83)$, and this may have raised an awareness of the value of small group activities in the perceptions of semester 1 students.

\section{Limitations of the study}

Although this study highlights findings which have relevance for those involved in medical and veterinary education, it has several limitations that should be considered. For example, the study sample relates to a group of students within one academic institution and one limited time period. Thus, its results should be generalized with caution. In addition, there were low numbers of students in some of the sex and preassigned age categories, so it was more difficult to identify statistically significant differences.

The researchers suggest that further work is necessary to explore the factors affecting classroom participation in greater detail. Individual student characteristics are only part of the story, in that the design and layout of the lecture hall, instructor factors, and the material being addressed during lectures all play a part in learner participation. Further work could involve focus group interviews to increase the level of detail on these factors obtained from learners. Finally, an observational study to identify actual classroom participation behavior, as compared with self-reported participation, could yield valuable information.

\section{Conclusion}

In this study, sex likely played a role in learner participation in the large group veterinary classroom. Male students were more likely than female students to participate in class and more likely to report feeling confident enough to participate in class. Female students commonly identified an aversion to public speaking as a factor holding them back from participation in the large group lecture setting. These are important findings for veterinary and medical educators wanting to improve learner participation in the classroom. Potential ways of addressing this challenge include addition of small group activities and audience response systems to lectures, and inclusion of training interventions in public speaking at an early stage of veterinary and medical curricula.

\section{Author contributions}

JM, SL, and DS conceived and coordinated the study, and drafted, tested, and implemented the questionnaire. JM and JB carried out the data analysis and interpretation. JM and JB drafted the manuscript. All authors read and approved the final manuscript.

\section{Disclosure}

The authors declare that they have no conflicts of interest in this work.

\section{References}

1. Brown G, Manogue M. Refreshing lecturing: a guide for lecturers. Med Teach. 2001;23:231-244.

2. Harden RM, Laidlaw JM. Essential Skills for a Medical Teacher: An Introduction to Teaching and Learning in Medicine. Edinburgh, Scotland: Churchill Livingstone; 2012.

3. Geske J. Overcoming the drawbacks of the large lecture class. College Teaching. 2012;40:151-154.

4. Graffam B. Active learning in medical education: strategies for beginning implementation. Med Teach. 2007;29:38-42.

5. Terenzini PT, Springer L, Pascarella ET, Nora A. Influences affecting the development of students' critical thinking skills. Res High Educ. 1995;36:23-39.

6. Weaver RR, Qi J. Classroom organization and participation: college students' perceptions. J Higher Educ. 2005;76:570-601.

7. Howard JR, James GH III, Taylor DR. The consolidation of responsibility in the mixed-age college classroom. Teach Sociol. 2002;30: 214-234.

8. Ross University School of Veterinary Medicine. Student Consumer Information. Available from: http://www.rossu.edu/student-consumerinfo.cfm. Accessed November 1, 2013.

9. Crawford M, MacLeod M. Gender in the college classroom: an assessment of the 'chilly climate' for women. Sex Roles. 1990;23:101-122.

10. Fassinger PA. Professors' and students' perceptions of why students participate in class. Teach Sociol. 1995;24:25-33.

11. Turk CL, Heimberg RG, Orsillo SM, et al. An investigation of gender differences in social phobia. J Anxiety Disord. 1998;12:209-223.

12. Reichenbach L, Brown H. Gender and academic medicine: impacts on the health workforce. BMJ. 2004;329:792-795.

13. Lofstedt J. Gender and veterinary medicine. Can Vet J. 2003;44: 533-535. 
14. Royal College of Veterinary Surgeons. Survey of the Veterinary Professions. London, UK: Royal College of Veterinary Surgeons; 2011.

15. Steinart Y, Snell L. Interactive lecturing: strategies for increasing participation in large group presentations. Med Teach. 1999;21: $37-42$.

16. Edmunds S, Brown G. Effective small group learning: AMEE Guide No 48. Med Teach. 2010;32:715-726.
17. North American Veterinary Medical Education Consortium. Roadmap for Veterinary Medical Education in the 21st Century. Washington, DC, USA; North American Veterinary Medical Education Consortium; 2011.

18. Royal College of Veterinary Surgeons. Day and Year One Competences: Essential Competences Required of the Veterinary Surgeon. London, UK: Royal College of Veterinary Surgeons; 2010.

\section{Publish your work in this journal}

Advances in Medical Education and Practice is an international, peerreviewed, open access journal that aims to present and publish research on Medical Education covering medical, dental, nursing and allied health care professional education. The journal covers undergraduate education, postgraduate training and continuing medical education including emerging trends and innovative models linking education, research, and health care services. The manuscript management system is completely online and includes a very quick and fair peer-review system. Visit http://www.dovepress.com/testimonials.php to read real quotes from published authors.

Submit your manuscript here: http://www.dovepress.com/advances-in-medical-education-and-practice-journal 